\title{
Introduction: the scope of complexity and its implications for policy
}

\section{John Finch and Magali Orillard}

The chapters included in this volume contribute to the established research tradition of complexity in economics and in the economy, and to a growing area within this of developing economic policy (Colander 2000; Foster and Metcalfe 2001). Our aim is to bring together a collection of related arguments and studies about complexity that consider different dimensions of the activity of policy and its consequences in the economy, undertaken within and among different organizations such as governments and companies.

In this introductory chapter we seek to sketch out a couple of themes that we think form a basis for making connections across the different contributions. These themes are: (1) assessing what policy is as an activity, given a complexity perspective, and (2) considering how a complexity approach may relate to an evolutionary one. Thorough investigation of these questions is of course beyond the scope of an editorial introduction, but we hope that in raising these questions, we can provide the reader with a basis for considering this collection in the round.

\section{A SHORT DISCUSSION OF COMPLEXITY}

What has come to be known as complexity, broadly interpreted, has a long and illustrious history among economists. Smith's system of the division of labour and development of knowledge is a self-organizing system of systems (Potts 2001a). Selective connections are crucial to Smith, Marshall, Menger and Hayek in bringing into focus connections between social and economic organization and the development of knowledge (Loasby 1999, 2001). Simon's substantial contribution is discussed elsewhere in this collection, especially in Jean-Luis Le Moigne's chapter. Foster (1993) returns to Marshall and develops the theme of time-irreversibility into a self-organizing and complex framework, itself an argument in sympathy with Young (1928), Richardson (1960) and Loasby and $_{\text {and }}(1978)_{9781845428044}$ 
Forming a canon is though, but one element of complexity research, of realizing that we have been undertaking something of this nature in theoretical and empirical analyses for a long time (Brown 1993; Dopfer et al. 2004, p. 268 fn. 9). We also have a style of undertaking empirical analysis through 'history-friendly modelling'. This has been undertaken in order to address the long-recognized conflicts inherent in endeavouring to provide explanations of historical and contextual phenomena in more general terms. 'History friendly' implies a combination of both informal or appreciative theories developed in situ, perhaps involving the formulation of 'stylized facts,' and established theories that purport to be of more general application. Further, researchers usually seek to articulate their findings in a manner which betrays an intention to be of more general application than a particular spatial and temporal context (Dopfer 2001; Potts 2001b). Groundbreaking examples include Arthur's (1994) El Farol problem, Härdle and Kirman's (1995) analysis of buying behaviour in the Marseille fish market, and Malerba et al.'s (1999) analysis of the computing industry.

An important feature of history friendly analysis and modelling is its inherent capacity to allow researchers to think through the consequences of things feasibly having been different. This is established in Nelson and Winter's (1982) industry simulations. Potts (2000) draws upon graph theory to describe the concept of adjacent spaces, which may as yet be unoccupied, and of unmade but feasible connections that characterize particular contexts. For Potts, the ontology of (broadly) economic space is described appropriately by networks - of made and unmade connections - and not fields. Further, the connections are loosely hierarchical, of systems and subsystems. Following Simon (1962), patterns of connections made and unmade imply subsystems within systems that are nearly-decomposable. And the condition of nearly-decomposable includes the potentially treacherous and ambiguous qualification of 'nearly'. In devising and enacting policies, the nearness of nearly is of critical importance (Loasby 1976).

Complexity is about emergent properties within systems, with these emergent properties necessarily betraying some form or degree of orderliness (Archer 1995; Delorme 2001). Complexity is also about processes and dynamics taking place within and across contexts located in time and space (Foster 1993). Emergence implies that there are, ontologically, levels because there are usually no simple ways of identifying a whole in terms of its parts and vice versa. Groups within firms are not smaller versions of the firm, industries are not summations of identical firms and firms are not smaller replications of industries. These distinctions of levels though are of little interest or relevance without processes and dynamics taking place over

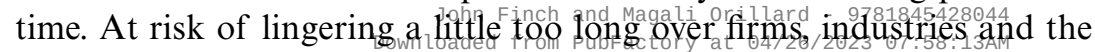


organization of production, Penrose's (1959) explanation of the growth of the firm continues to be a source of inspiration for complexity researchers.

Penrose's firms produce or accumulate free resources inevitably as a consequence of their normal activities and the normalization of these activities. Some entrepreneurs or managers pursue strategies of growth and devote resources to capturing these free resources and applying them to perceived opportunities. Something like free resources can be the subject of managerial deliberation and planning, given a subjective vision, but in the context of an acquired and inherited way of doing things and way of seeing things. Note that these seemingly free resources, released through processes of routinization and familiarity, require deliberation, planning and integration around a vision. The process is dynamic. Cyert and March (1963) also include resources that are strictly non-productive, and so potentially free, in their explanation of the firm. Following Cyert and March, these resources are tied up in organizational slack, which is essential in allowing a firm to adapt in the face of uncertainty, and also to absorb disputes that inevitably arise internally. Slack prevents disorder, which is another dimension of contributing to growth.

Only fairly recently have researchers begun undertaking empirical analysis of the potential for disorder caused by the strategic process of capturing resources from within the firm and directing these at additional perceived opportunities. Flaherty (2000) provides an explanation of experimentation in semiconductor production. The focus of experimentation is again design, but this time the planning is as much concerned with the avoidance of unintended creative destruction of established practices as it is with the articulation of new visions. Complexity in the economy, then, is about order as self-organization or at least organization from within a system (Thompson 1967; Loasby 1991; Foster 1993; Kauffman 1993; Potts 2000). Order in complex systems must be explained rather than assumed and is an appropriate focus of policy deliberation. Following Luhmann (1995), complexity embodies the potential for order but, a priori, order is improbable.

\section{POLICY PRESUMING COMPLEXITY}

Policy analysis given complexity differs radically from a good deal of that set out in other traditions of economic research. The opportunities for system closure and aggregation implied by Walrasian welfare economics cannot be assumed by complexity researchers. Rather, complexity researchers can provide explanations of on-going tendencies for increasing returns and for

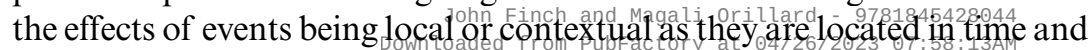


space. Given complexity, with its ontology of networks, contexts, selective connections, subsystems and systems, and near-decomposability, we have little option but to adopt a broad understanding of policy.

Policy is like strategy in that it can involve (in no particular order): an active or deliberative capture and review of a pattern (or range of feasible patterns) of connections around some issue; boundary drawing around issues and elements considered to be proximate, so designating other elements as distant; articulating visions of why and how things can be different; selecting a vision and course of activities consistent with it; undertaking a set of activities in motivation of a vision; a rejection of other activities on the basis of them not being consistent with the vision; and reviewing activities to consider how things are turning out with respect to the vision. Policy-makers and strategists may consider it expedient to undertake a trial or experiment, and may have the opportunity of so doing. This is notwithstanding difficulties in isolating and interpreting causes and effects, and drawing sound inferences from observations and codifications of subsequent events, whether expected or unexpected (Hendry and Seidl 2003).

Policy and strategy share considerable common ground, both in terms of requiring similar types of activities, or requiring similar sets of capabilities, and in terms of the nature of contexts within which policy and strategy are appropriate or relevant activities. But by drawing attention to policy and strategy as activities, and also as taking place in more or less appropriate contexts, we see that they are not synonymous, even though distinctions may be subtle. Policy is intended to be more general than strategy which in turn is more general than activities. Individuals, organizations and governments can, for example, all formulate policies, strategies and actions. Some actions can be undertaken with the aim of formulating and undertaking strategies and policies, and some strategies may be pursued with the aim of shaping one's own or others' policies, strategies or activities.

Policies have a more pronounced social or public dimension to them, as they speak of a commitment to undertaking some actions and so excluding other actions in the event of envisaged and so feasible future circumstances. Policy is associated with the acquisition, embodiment, enhancement and protection of reputation and legitimacy, in processes of formulating policies. These public contingencies are all put at risk in formulating visions of feasible future events, deciding upon which actions to include and which to exclude, in then deciding whether actual events fit into those envisaged by the policy, and in being accountable (even if only to one's self). A strategy may be articulated or inferred by 'outsiders', but the notion of 'outsider' is different in the context of policy as policy is by its nature articulated and codified in the expectation of it being communicated and understood widely by others. All these episodessonn 
of and accounting for policy may well merge with strategy, but the bigger picture, the connecting thread, and the overall sense of current and future accountability, distinguish policy from strategy.

The differences between activities, strategies and policies can be interpreted as matters of degree rather than type, but the distinctions are significant. The very idea of these being different is more easily understood given a network ontology and graph-theoretic representation of complexity. Policy-making, more than activities and strategies, is about agents - more or less powerful agents - deliberating over order, or more accurately types of orders as order itself cannot be presumed to be in some way singular and neutral. These deliberations, whether undertaken, for example, individually, or within organizations, or in governments, are time and resource consuming, so, of course, impose opportunity costs.

Economists have well-established explanations of the activities involved in policy-making where agents are modelled as if possessing rational or adaptive expectations. But these models presume policy-making taking place 'off-line' and outside the economic system in question (often a national economy). By assuming complexity, and so an economic system and connected subsystems, policy is an activity within this system, involved in affecting an emerging order. Even simulations and other attempts at learning-before-doing (or superficially 'off-line') can leak out selectively into other contexts through network connections.

Our discussion of why we have activities centred on policy has functionalist overtones, in that we have constructed an explanation of policy activities predicated upon there being something called 'policy'. Prima facie, policymaking is required as part of the process of coordinating activities, plans, strategies and other policies at different levels or in connected subsystems. Given shared expectations of the fixity or rigidity inherent in policies alongside complexity in the broadly economic systems and subsystems, policies are likely to be abandoned sooner or later. Events develop in unforeseen ways and subsystem boundaries reveal themselves to be different, or change anyway perhaps as unintended consequences of policies, despite the power of policies to shape agents' plans. But complexity can come to the rescue of policy-making, and the social reputations and legitimacies of those undertaking policy-making endeavours, by providing some grounds for setting-out reasons for modifying or abandoning policies.

\section{COMPLEXITY AND EVOLUTION}

Complexity provides a particular perspective on evolutionary explanations

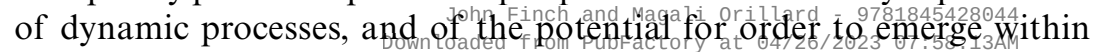


these dynamic processes (Kauffman 1993). The nature of the distinction between complexity and other evolutionary approaches is difficult to pin down because of differences in the ways in which researchers have adopted evolutionary terminology. Ambiguous interpretations of evolution permit complexity to co-exist with more functionalist ideas of survivor selection, with Lamarckian processes of heredity, and with Darwinian explanations. Universal Darwinism or Universal Adaptation is a precise model and has presented researchers among broadly economic phenomena with greater challenges. Loasby (2002) has warned against the uncritical application of biological models of evolution. Hodgson (2002), Knudsen (2002) and Hodgson and Knudsen (2004) start instead with a Universal Darwinian or Universal Adaptationist ontology (that is, one that begins neither in social nor life sciences) and have applied this to models of firms, workgroups within firms, industries and markets.

In distinguishing complexity from other similar or complementary explanations within evolutionary analysis, we can draw on Simon (1962) and Potts (2000). Simon argues that social systems that are broadly hierarchical, and characterized by near-decomposability, are likely to be favoured by evolutionary processes of selection. This insight has since been developed into the modularity research tradition (Sanchez and Mahoney 1996; Brusoni and Prencipe 2001; Langlois 2002). Given near-decomposability, modules of activities, connected by an architecture (of an overall system and its groups, modules or subsystems), standards (especially of communication, of making utterances in the expectation that these will be understood, and that responses and non-responses can also be interpreted) and interfaces (of the proximity of groups, modules or subsystems) are expected generally to be better at absorbing and localizing disruptive shocks without threatening the entire integrity and functioning of an overall system.

Potts (2000, p.91) articulates the hypothesis of 'evolution towards complexity' from within a graph-theoretic or network framework. Simplicity and near-chaos are other broad descriptions of patterns of connections within systems. Simplicity implies a low ratio of connectivity to elements, so constrained patterns of communication and missing links between elements that may, if connected, be productivity enhancing. Near-chaos offers too high a ratio of connections to elements within a social system, with none of the localizing effects of modularity discussed by Simon.

Complexity and evolution by selection are complements in the argument of evolution towards complexity because the processes of selection and retention are schematically external to the system being discussed, of being in that system's environment. At risk of gross simplification, while agents in systems, such as firms or industrial networks, can choose different

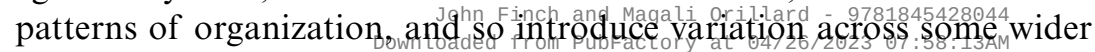


population, which tend towards routine over time through repetition, selection is in markets. And markets, as a means or location of selection, can form environments for the (complex) systems in question. If the systemenvironment boundary or horizon is difficult to draw in theory or practice, the role of selection becomes ambiguous.

Knudsen (2002) has addressed Nelson and Winter's (1982) research agenda by arguing that routines could in principle have the roles of both replicator and interactor. Following Cohen et al.'s (1996) discussion, we know that necessarily social or inter-personal routines can be 'fine-grained' or 'large-grained', and that each may have different roles or functions when considered in complex and evolutionary terms. We may have simultaneous processes of variation, selection and retention on-going among different 'levels' of economic phenomena, or we need to identify the most likely levels and hence system boundaries, within which to understand variation, selection and retention.

Hodgson and Knudsen (2004) argue that firms rather than work groups within firms may appropriately be thought of as interactors within a Universal Darwin or Universal Adaptation framework. Without specifically drawing on contributions to modularity, they argue that work groups are too dependent on firms so are insufficiently decomposable from firms - and so presumably from other work groups in a particular firm - to interact independently within an environment with other agents. This may be compared with Brusoni and Prencipe's (2001) analysis of modularity, in which they argue that agents called system integrators have a necessary role in ensuring system and module integrity within and also across firms. In other words, architecture, interfaces and standards are not autonomous or self-organizing guarantors of near-decomposability, but require active management and authority. So selection in the Universal Darwinian sense can infiltrate the boundaries of the firm.

The idea of firms being organized as 'higher-level' entities or systems that draw upon work groups is only one model of the organization of productive activities. There are occasions where work groups and firms coincide, but there are other common circumstances where activities are undertaken as joint ventures or other coalitions, especially in industries characterized by projects. Further, we should ask why stop at firms? Araujo et al. (2003) map the 'multiple boundaries of firms'. Holmen and Pedersen (2003) draw out different means, especially intensities, of communication in the activity of 'strategizing' among networks of firms. Such cases are analogous to firms and work groups, only this time the work group could be a 'corresponding firm' instead of a work group, with means of connection

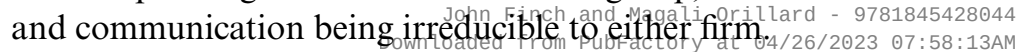


The complexity and Universal Darwinism or Universal Adaptation approaches seem to envisage similar ontologies. Researchers and other agents also have a good deal of discretion in matching boundaries or horizons to their social systems, given an understanding of a problem. But the focus of research questions has at least a different emphasis. In complexity, selforganization is within a system, and probably involves subsystems and sub-subsystems. In Universal Darwinism or Universal Adaptation, the overriding interest in selection requires that systems are varied, stable, connected through selection itself so being nearly-decomposable, and solving of the replicator-interactor identity. Even if we can push selection beyond a system's boundaries - that is, if we can identify system boundaries - we still have vital research questions to resolve in assessing how and whether a system attains its essential 'systemness'.

We could go further in our adoption Universal Darwinism or Universal Adaptation, perhaps as 'Ultra-Darwinism' (Stoelhorst, this volume). Following Dawkins (1989) and Maynard Smith (1982) we should identify agents in the role of interactors that have the role of housing and being instructed by gene-like replicators. This ontology has been influential among evolutionary game theorists, who have followed Maynard Smith in seeking to explain order in systems in the identification of evolutionarily stable strategies (Gintis 2000).

Following Kauffman (1993), complexity and self-organization are complementary research questions to evolution by natural selection. Complexity takes the focus from natural selection, admitting that it may at times act weakly, but without disorderly consequences. Instead, we may focus first on how broadly economic activities take on the characteristics of fairly orderly and on-going or autopoietic social-economic systems (Luhmann 1995). Indeed, Dopfer et al. (2004, p. 266) argue that a complex rule structure, which is how they explain knowledge, is of greater importance than selection processes as it aids our understanding of variety. Further, they advise that we view broadly economic phenomena, systemically, as one of a population of actualizations of some 'generic rule'.

For some questions and contexts, system boundaries might coincide with firm boundaries, as argued by Hodgson and Knudsen (2004). In other circumstances, it may be sensible - and in accordance with Hodgson and Knudsen's implicit criteria of near-decomposability - for researchers, agents and policy-makers alike to consider the system boundary as extending to consumers as producers (Bianchi 1998) or consumers as innovators (von Hippel 1988). In still others, the project organization might be the appropriate system boundary, within, between or in the absence of companies. 


\section{AN OUTLINE OF THIS COLLECTION}

We have organized the chapters of this collection into four parts. The first part is an introduction to the key themes of complexity and economics. Part II addresses the tensions of historical and general explanations, and of complexity and evolution. Part III takes the complexity and evolution argument further by addressing the role of transaction costs in guiding patterns of organization. Part IV is about policy-making in explicitly complex systems, including companies, industries and governments.

We begin the collection with a chapter based on an interview with W. Brian Arthur, conducted on behalf of the European Association for Evolutionary and Political Economy by Robert Delorme and Geoffrey Hodgson. Arthur explains how his interest in complex systems developed, in part through a growing dissatisfaction with neoclassical explanations that seemed to rule out the possibility of persistent increasing returns among some economic activities. As researchers, we are advised to develop and redevelop theories that help us understand and explain the economy as the structures of the economy are continually changing too. Further, we are urged to 'fearlessly explore', as the field of complexity and economics has benefited from initial insights that have opened up rather than 'cleaned up' the research tradition.

Alan Kirman's chapter reviews and develops the concept of self-organizing systems. We are taken back to our early experiences of economics, and of how troubling we may have found our understandings of coherent aggregate phenomena, given our other understandings of the myriad of motives and means for undertaking economic interactions, communications and exchanges. We encounter history-friendly modelling of demand at the Marseille fish market, and, drawing upon graph theory, envisage the structuring impacts on economic behaviour of more or less complex patterns of interactions.

Jean-Louis Le Moigne presents an argument about 'complexity and political economy: implications for economic science' and of 'complexity and economic science: implications for political economy'. This is developed from reviewing Herbert Simon's contributions to understanding economics, organization and complexity. The main argument is that complex systems are obscured rather than made more intelligible if we adopt the conventional modelling strategy of simplification in economic and econometric modelling.

The second part of this collection comprises three chapters that address some of the fundamental principles of complexity. Uta-Maria Niederle presents a detailed and 'history-friendly' analysis of the emergence of

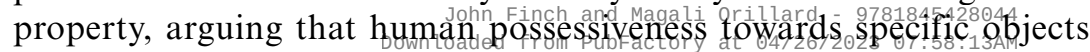


together with commitments and preferences to legal regimes and principles shape patterns and outcomes of property relations. This general argument is though quite consistent with particular societal manifestations, or paths, from property to possession, depending on particular environmental and cultural endowments.

Eyüp Özveren also draws upon historical analysis, and particularly the theorizing of Fernand Braudel, in which deeper structures provide some orderly basis for seemingly chaotic instances of events. Braudel's analysis presents a 'triple division' or hierarchy of: an elementary economy of material life, a domain of economic life within a market zone, and capitalism. This chapter brings a further perspective on the possibilities for 'historyfriendly' theorizing; in distinction to what he argues is the historicism of some institutional economics and the ahistoricism of new institutional economics and of new economic history.

Jan-Willem Stoelhorst addresses the second of the two themes highlighted in this introductory chapter by investigating and questioning the applicability of what he terms the 'Ultra-Darwinist' approach among firms and industries. A second Darwinian approach is proposed, which Stoelhorst calls a 'Naturalist' theory. Both categories fit within Universal Darwinism, of recognizing the relevance of such arguments across social and life sciences. Stoelhorst's argument is developed further through a case study of Intel, which is presented as a case of multi-level selection and adaptation.

The third part includes three chapters that each present an analysis of transaction cost economics in the context of organizing and so connecting broadly economic activities.

Elodie Bertrand investigates the historical circumstances of Coase's famous 'lighthouses argument' and shows instead that the State had a much more supportive and involved role in the provision of lighthouses in England and Wales. Bertrand also draws upon the provision of lighthouses in France to demonstrate how the involvement of the State assisted innovation processes, and also the standardization and so replication of production and technology solutions. The role of transaction costs in affecting the connections across productive activities is also developed in two chapters, by Alexander Lascaux and by Gráinne Collins. Lascaux argues that transaction cost authors are mistaken in seeing trust as an auxiliary factor that can be planned, developed and relied upon in practice to help close exchanges where formal contractual means prove unreliable. Indeed, one of the arguments that Lascaux investigates is the possibilities that trust may become excessive in terms of causing additional transaction costs. One implication of Lascaux's chapter is that trust can be understood from within

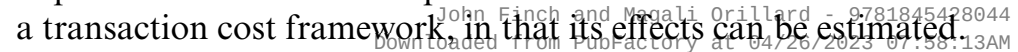


Gráinne Collins adopts a critical stance in investigating whether trust can be developed by managers as an alternative to bureaucratic control. The fundamental and recursive feature of trust for Collins is that trusting is both a 'leap in the dark' and also the subject of calculation. We trust the means of calculation, its data, measurements, and the means of measurement, formula, theories, assumptions, qualifications, capabilities, competence, motivations, ethics and commitments of others. These are probably essential features of decisions and of trust. The same applies to designing and building trust.

The final part of this collection is made up of four chapters that develop and report empirical analyses undertaken from a complexity perspective. Virginia Acha and Stefano Brusoni question the life-cycle theory of firms, industries and technologies in their investigation of the mature industry of tyre production. They show how changes in technology and organization are both on-going despite the typical symptom of maturity - the development of and then settling into oligopoly - being well-established. Maturity and oligopoly have only changed the nature of complexity both in organizational and technological terms. Indeed, complexity has increased as the industry's knowledge-base has extending during maturity to cover other distinct industrial and research groupings.

Norio Tokumaru assesses how codification of technological knowledge and also the complexity of technological knowledge have interacted upon one another and upon the organization of production in the case of semiconductor production. Codification has contributed to the emergence of new organizational forms in semiconductor production, but the complexity of technology and of knowledge development has led to a wider diversity of organizational forms than might have been the case had codification per se been the dominant factor in affecting the organization of production. The reader is referred back to the chapters of the third part of this book to consider further the connections between complexity and transaction costs.

Lionel Nesta and Ludovic Dibiaggio question whether technology is a basis for us to proceed in investigating the reasons and consequences of firms differing. Instead, they investigate the sources of technological differentiation or specialization itself among companies in the biotechnology industry and find a conceptual distinction between 'bodies of understanding' (usually codified) and 'bodies of practice' (usually narrowly context-specific within firms) helpful. Nesta and Dibiaggio's analysis also refers to life-cycle effects, with technological differentiation being more prominent in strategies aimed at establishing niches and leaderships, but technology convergence being a symptom in their analysis of maturity. It is especially in these more mature industry circumstances that 'bohi Finch and Magali, briclard - 9781845428044 
Cristina Matos's chapter shifts the focus of policy-making from technology strategy to employment relations, and so involves policy-making among governments as well as within companies and by employees. Matos considers post-socialist transformation among companies in Hungary and in the Czech Republic as these involve different instances of employment 'informalization'. Government policy-makers are implicated in processes of normalization, thereby stabilizing particular initiatives that can emerge from companies, and providing a basis in the form of feedback for further company-led initiatives.

\section{ACKNOWLEDGEMENTS}

We are grateful to Fiona Leverick and Robert McMaster for comments and suggestions on an earlier draft of this chapter. The usual disclaimer applies.

\section{REFERENCES}

Araujo, Luis, Anna Dubois and Lars-Erik Gadde (2003), 'The multiple boundaries of the firm', Journal of Management Studies, 40, 1255-77.

Archer, Margaret (1995), Realist Social Theory: The Morphogenetic Approach, Cambridge: Cambridge University Press.

Arthur, W. Brian (1994), 'Bounded rationality and inductive behaviour (the El Farol problem)', American Economic Review Papers and Proceedings, 84, 406-11.

Bianchi, Marina (ed.) (1998), The Active Consumer: Novelty and Surprise in Consumer Choice, London and New York: Routledge.

Brown, Vivienne (1993), 'Decanonizing discourses: textual analysis and the history of economic thought', in Willie Henderson, Tony Dudley-Evans and Roger Backhouse (eds), Economics and Language, London and New York: Routledge, pp. 64-84.

Brusoni, Stefano and Andrea Prencipe (2001), 'Unpacking the black box of modularity: technologies, products and organizations', Industrial and Corporate Change, 10, 179-205.

Cohen, Michael, R. Burkhart, Giovanni, Dosi, Massimo, Egidi, Luigi, Marengo and Massimo Warglien (1996), 'Routines and other recurring action patterns of organizations: contemporary research issues', Industrial and Corporate Change, 5, 653-98.

Colander, David (ed.) (2000), The Complexity Vision and the Teaching of Economics, Cheltenham, UK and Northampton, MA, USA: Edward Elgar.

Cyert, Richard and James March, 1963, A Behavioral Theory of the Firm, Englewood Cliffs, NJ: Prentice-Hall.

Dawkins, Richard (1989), The Selfish Gene, new edition, Oxford and New York:

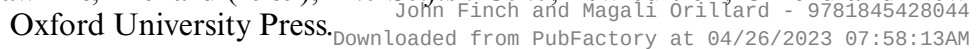


Delorme, Robert (2001), 'Theorizing complexity', in John Foster and J. Stanley Metcalfe (eds), Frontiers of Evolutionary Economics. Competition, SelfOrganization and Innovation Policy, Cheltenham, UK and Northampton, MA, USA: Edward Elgar, pp. 80-108.

Dopfer, Kurt (2001), 'History-friendly theory in economics: reconciling universality and context in evolutionary analysis', in John Foster and J. Stanley Metcalfe (eds), Frontiers of Evolutionary Economics: Competition, Self-Organization and Innovation Policy, Cheltenham, UK and Northampton, MA, USA: Edward Elgar, pp. 160-87.

Dopfer, Kurt, John Foster and Jason Potts (2004), 'Micro-meso-macro', Journal of Evolutionary Economics, 14, 263-80.

Flaherty, M. Thérèse (2000), 'Limited enquiry and intelligent adaptation in semiconductor manufacturing', in Giovanni Dosi, Richard Nelson and Sidney Winter (eds), The Nature and Dynamics of Organizational Capabilities, Oxford: Oxford University Press, pp. 99-123.

Foster, John (1993), 'Economics and the self-organisation approach: Alfred Marshall revisited', Economic Journal, 103, 975-91.

Foster, John and J. Stanley Metcalfe (2001), 'Modern evolutionary economic perspectives: an overview', in John Foster and J. Stanley Metcalfe (eds), Frontiers of Evolutionary Economics: Competition, Self-Organization and Innovation Policy, Cheltenham, UK and Northampton, MA, USA: Edward Elgar, pp. 1-16.

Gintis, Herbert (2000), Game Theory Evolving. A Problem-Centered Introduction to Modeling Strategic Behavior, Princeton, NJ: Princeton University Press.

Härdle W. and Alan Kirman (1995), 'Non classical demand: a model-free examination of price quantity relations in the Marseille fish market', Journal of Econometrics, 67, 227-57.

Hendry, John and David Seidl (2003), 'The structure and significance of strategic episodes: social systems theory and the routine practices of strategic change', Journal of Management Studies, 40, 175-96.

Hodgson, Geoffrey (2002), 'Darwinism in economics: from analogy to ontology', Journal of Evolutionary Economics, 12, 259-81.

Hodgson, Geoffrey and Thorbjørn Knudsen (2004), 'The firm as an interactor. firms as vehicles for habits and routines', Journal of Evolutionary Economics, 14, 281-307.

Holmen, Elsebeth and Ann-Charlotte Pedersen (2003), 'Strategizing through analyzing and influencing the network horizon', Industrial and Marketing Management, 32, 409-18.

Kauffman, Stuart (1993), The Origins of Order: Self-Organization and Selection in Evolution, Oxford: Oxford University Press.

Knudsen, Thorbjørn (2002), 'Economic selection theory', Journal of Evolutionary Economics, 12, 443-70.

Langlois, Richard (2002), 'Modularity in technology and organization', Journal of Economic Behavior and Organization, 49, 19-37.

Loasby, Brian (1976), Choice, Complexity and Ignorance, Cambridge: Cambridge University Press.

Loasby, Brian (1978), 'Whatever happened to Marshall's theory of value', Scottish Journal of Political Economy, 25, 1-12.

Loasby, Brian (1991), Equilibrium and Evolution in Economics, Manchester: Manchester University Pfess John Finch and Magali orillard - 9781845428044 
Loasby, Brian (1999), Knowledge, Institutions and the Evolution in Economics, London and New York: Routledge.

Loasby, Brian (2001), 'Time, knowledge and evolutionary dynamics: why connections matter', Journal of Evolutionary Economics, 11, 393-412.

Loasby, Brian (2002), 'The evolution of knowledge: beyond the biological model', Research Policy, 31, 1227-39.

Luhmann, Niklas (1995), Social Systems, trans. by John Bednarz Jr. with Dirk Baecker, Stanford, CA: Stanford University Press [originally published in German in 1984].

Malerba, Franco, Richard Nelson, Luigi Orsenigo and Sidney Winter (1999), 'History-friendly models of industry evolution: the computing industry', Industrial and Corporate Change, 8, 3-40.

Maynard Smith, John (1982), Evolution and the Theory of Games, Cambridge and New York: Cambridge University Press.

Nelson, Richard and Sidney Winter (1982), An Evolutionary Theory of Economic Change, Cambridge, MA: Belknap Press of Harvard University Press.

Penrose, Edith (1959), The Theory of the Growth of the Firm, Blackwell: Oxford.

Potts, Jason (2000), The New Evolutionary Microeconomics. Complexity, Competence and Adaptive Behaviour, Cheltenham, UK and Northampton, MA, USA: Edward Elgar.

Potts, Jason (2001a), 'Knowledge and markets,' Journal of Evolutionary Economics, 11, 413-31.

Potts, Jason (2001b), 'Commentary: history-friendly theory in economics. reconciling universality and context in evolutionary analysis', in John Foster and J. Stanley Metcalfe (eds), Frontiers of Evolutionary Economics. Competition, Self-Organization and Innovation Policy, Cheltenham, UK and Northampton, MA, USA: Edward Elgar, pp. 188-94.

Richardson, George (1960), Information and Investment. A Study in the Working of the Competitive Economy, Oxford: Clarendon Press.

Sanchez, Ron and Joseph Mahoney(1996), 'Modularity, flexibility and knowledge management in product and organization design', Strategic Management Journal, 17 (Winter special issue), 63-76.

Simon, Herbert (1962), 'The architecture of complexity', Proceedings of the American Philosophical Society, 106, 467-82.

Thompson, James (1967), Organizations in Action, New York: McGraw-Hill.

von Hippel, Eric (1988) The Sources of Innovation, Oxford and New York: Oxford University Press.

Young, Alyn (1928), 'Increasing returns and economic progress', Economic Journal, 38, $527-42$. 